\title{
PERANAN POSYANDU LANSIA DALAM MENINGKATKAN KESEHATAN MASYARAKAT DI KELURAHAN KERTOSARI, KECAMATAN BABADAN, KABUPATEN PONOROGO TAHUN 2015
}

\author{
Mey Yustinasari*
}

\begin{abstract}
Abstrak
$\mathrm{P}$ osyandu lansia berperan meningkatkan kesehatan masyarakat khususnya para lansia sehingga lansia memiliki jiwa yang sehat dan sejahtera. Dengan demikian, penelitian ini bertujuan untuk mendeskripsikan kesehatan lansia, pelaksanaan dan peranan Posyandu Lansia di Kelurahan Kertosari, Kecamatan Babadan, Kabupaten Ponorogo. Penelitian ini dilaksanakan di Kantor Kelurahan Kertosari, Kecamatan Babadan, Kabupaten Ponorogo selama empat bulan, yaitu pada Maret sampai dengan Juni 2015.Penelitian ini menggunakan pendekatan kualitatif. Sumber data yang digunakan adalah sumber primer dan sekunder. Pengumpulan data menggunakan observasi, wawancara, dan dokumentasi.Teknik keabsahan data menggunakan triangulasi sumber. Analisis data menggunakan reduksi data, penyajian data, dan penarikan kesimpulan dan verifikasi. Hasil penelitian menunjukkan bahwa kesehatan lansia di Kelurahan Kertosari, Kecamatan Babadan, Kabupaten Ponorogo ada yang sadar kesehatan dan ada yang tidak sehingga lansia yang tidak sadar kesehatan banyak mengalami masalah kesehatan. Para lansia tersebut rutin mendatangi Posyandu Lansia yang diadakan setiap satu bulan sekali pada Rabu minggu pertama mulai pukul 07:00 WIB. Di sini, para lansia tidak hanya dapat memeriksakan kesehatan tetapi juga menghibur diri karena Posyandu Lansia berperan sebagai pelayanan kesehatan, tempat konseling, dan tempat bersilaturahmi.
\end{abstract}

Kata Kunci : Kesehatan, Posyandu, dan Lansia

* Mahasiswa Prodi PPKn IKIP PGRI Madiun 
PENDAHULUAN

Menurut Fatmah, data 2010 populasi lansia di Indonesia rata-rata 7,5\% dari jumlah total penduduk dan dalam waktu 20 tahun lagi jumlah lansia Indonesia akan melebihi balita. WHO mengatakan bahwa milenium ini ditandai dengan pergeseran gerontologis (gerontologocal shift), jumlah lansia dengan permasalahannya akan jauh lebih besar, lebih serius dan lebih kompleks (Fatmah, 2010: 3).

Lansia sering dianggap sebagai golongan yang lemah tetapi sesungguhnya lansia memiliki peran yang berarti bagi masyarakat. Lansia memiliki penalaran moral yang bagus untuk generasi dibawahnya. Lansia memiliki semacam gairah yang tinggi karena secara alami, manusia akan cenderung memanfaatkan masa-masa akhirnya secara optimal untuk melakukan pewarisan nilai dan norma. Hal ini justru mempermudah untuk membina moral anak-anak.

Mengingat kondisi dan permasalahan lansia tersebut, penanganan masalah lansia harus menjadi prioritas, karena permasalahannya terus berpacu dengan pertambahan jumlahnya. Seiring dengan semakin meningkatnya populasi lansia, pemerintah telah merumuskan berbagai kebijakan pelayanan kesehatan lansia yang ditujukan untuk meningkatkan derajat kesehatan dan mutu kehidupan lansia dalam mencapai masa tua bahagia dan berdaya guna dalam kehidupan masyarakat sesuai dengan keberadaannya.

Masalah kesehatan yang sering ditemukan di Indonesia perlu dibagi menjadi beberapa kelompok, antara lain masalah perilaku kesehatan, lingkungan, genetik dan pelayanan kesehatan yang menimbulkan berbagai masalah lanjutan seperti masalah kesehatan ibu dan anak, masalah gizi dan penyakit-penyakit menular maupun tidak menular. Masalah kesehatan tersebut dapat terjadi pada masyarakat secara umum atau komunitas tertentu seperti kelompok rawan (bayi, balita dan ibu), kelompok lanjut usia dan kelompok pekerja (Nengah, 2012: 1).

Undang-Undang Dasar 1945

Bab XA tentang Hak Asasi Manusia Pasal 28H Ayat (1) dijelaskan bahwa 
"Setiap orang berhak hidup sejahtera lahir dan batin, bertempat tinggal, dan mendapatkan lingkungan hidup yang baik dan sehat serta berhak memperoleh pelayanan kesehatan" Oleh karena itu, pelayanan kesehatan bagi masyarakat perlu ditingkatkan untuk meningkatkan kesehatan masyarakat di Indonesia.

Winslow (dalam Soekidjo, 2005: 17-18) memberikan pendapat bahwa kesehatan masyarakat (public health) adalah ilmu, seni atau upayaupaya untuk mencegah penyakit, memperpanjang hidup, dan meningkatkan kesehatan serta masalah-masalah yang mengganggu kesehatan masyarakat melalui usahausaha pengorganisasian masyarakat. Pelayanan kesehatan yang termasuk dalam kelompok pelayanan kesehatan masyarakat (public health services) ditandai dengan cara pengorganisasian yang umumnya secara bersama-sama dalam satu organisasi. Tujuan utamanya untuk memelihara dan meningkatkan kesehatan, mencegah penyakit, dengan sasarannya terutama untuk kelompok masyarakat (Wahid, 2009: 141).
Berdasarkan Undang-Undang Kesehatan Nomor 36 Tahun 2009 Pasal 139, dikatakan bahwa pemerintah wajib menjamin ketersediaan fasilitas pelayanan kesehatan dan memfasilitasi kelompok lanjut usia untuk dapat tetap hidup mandiri dan produktif secara sosial dan ekonomis. Oleh karena itu, diperlukan upaya pelayanan kesehatan terhadap lansia dengan membentuk Posyandu Lansia, (Majelis Permusyawaratan Rakyat 2009: 26).

Sebagai wujud nyata dari usaha pemerintah ini adalah dengan pelayanan kesehatan Posyandu Lansia. Posyandu lansia adalah suatu wadah pelayanan kepada lanjut usia di masyarakat, yang proses pembentukan dan pelaksanaannya dilakukan oleh masyarakat bersama Lembaga Swadaya Masyarakat (LSM), lintas sektor pemerintah dan nonpemerintah, swasta, organisasi sosial, dan lain-lain (Komisi Nasional Lanjut Usia, 2010: 5).

Pelayanan kesehatan lansia tingkat dasar adalah puskesmas dan pelayanan tingkat lanjutan adalah rumah sakit.Bentuk pelayanan pada Posyandu Lansia tidak hanya 
mencankup upaya kesehatan yaitu pemeriksaan kesehatan fisik dan mental emosional yang dicatat dan dipantau dengan Kartu Menuju Sehat (KMS) tetapi juga meliputi upaya sosial dan karya serta pendidikan. Hal ini dikarenakan permasalahan yang dihadapi lanjut usia bersifat kompleks, tidak hanya masalah kesehatan namun juga masalah sosial, ekonomi dan pendidikan yang saling terkait satu sama lainnya, (Komisi Nasional Lanjut Usia, 2010: 21). Dengan demikian, Posyandu Lansia sangat diperlukan. Posyandu Lansia ini dapat membantu lansia dengan kebutuhannya sehingga para lansia tidak merasa terabaikan di dalam masyarakat.

\section{METODE PENELITIAN}

Metode penelitian yang digunakan di dalam penelitian ini adalah penelitian deskriptif kualitatifyang mengarah pada pendeskripsian secara rinci dan mendalam mengenai kondisi tentang yang sebenarnya terjadi dan sesuai dengan yang ada di lapangan. Metode penelitian kualitatif menurut Sugiyono(2013: 9) adalah metode penelitian yang digunakan untuk meneliti pada kondisi objek yang alamiah, peneliti sebagai instrumen kunci, teknik pengumpulan data secara trianggulasi, analisa data bersifat induktif, dan hasil penelitian kualitatif lebih menekankan makna pada generalisasi.

Penelitian lebih menggunakan pendekatan antarpersonal. Artinya selama proses penelitian, akan lebih banyak mengadakan kontak atau berhubungan langsung dengan masyarakat, lansia, dan tenaga kesehatan di sekitar lokasi penelitian.

Sumber data di dalam penelitian kualitatif menurut Lofland (dalam Moleong, 2002: 112) ialah kata-kata, dan tindakan selebihnya adalah data tambahan seperti dokumen dan lain-lain. Sementara itu, Sugiyono (2013: 225) menyebutkan bahwa sumber data yaitu sumber data primer dan sumber data sekunder. Sumber data primer yaitu data yang langsung dari masyarakat baik yang dilakukan melalui wawancara, observasi dan alat lainnya. Sumber data sekunder yaitu sumber data yang berupa dokumen yang secara tidak langsung 
memberikan informasi kepada peneliti.

Miles dan Huberman (dalam Sugiyono, 2013: 246-253) analisis

Penelitian ini dilaksanakan di Kantor Kelurahan Kertosari, Kecamatan Babadan, Kabupaten Ponorogoselama empat bulan, yaitu pada Maret sampai dengan Juni 2015. Rincian kegiatan secara garis besar meliputi tahap persiapan, tahap pelaksanaan dan tahap penyelesaian. Teknik pengumpulan data dalam penelitian ini dilakukan dengan teknik observasi, wawancara, dan dokumentasi.

\section{Penelitian}

kualitatif memerlukan teknik keabsahan data (validitas data). Oleh karena itu, dibutuhkan cara untuk dapat memenuhi kriteria kredibilitas data. Teknik keabsahan data pada penelitian ini,menggunakan triangulasi data (yaitu triangulasisumber) yang berfungsi mengumpulkan data dari berbagai sumberdata. Data yang sama akan terlihat kebenarannya apabila digali dari berbagai sumber data seperti dokumen, arsip, hasil wawancara, dan hasil observasi.

Teknik analisis data dalam penelitian ini menggunakan teknik analisis data interaktif. Menurut data interaktif mengemukakan bahwa aktivitas dalam analisis data kualitatif dilakukan secara interaktif dan berlangsung secara terus menerus sampai tuntas sampai akhir penelitian sehingga datanya jenuh. Rangkaian aktivitas yang dilakukan dalam proses analisis interaktif berbentuk interaksi antar komponen yaitu reduksi data, penyajian data, dan penarikan kesimpulan dan verifikasi.

\section{HASIL DAN PEMBAHASAN}

1. Kesehatan Masyarakat di Kelurahan Kertosari, Kecamatan Babadan, Kabupaten Ponorogo Tahun 2015

Kelurahan Kertosari, Kecamatan Babadan, Kabupaten Ponorogo memiliki jumlah penduduk sangat banyak dan setiap tahunnya selalu meningkat dengan adanya kelahiran yang tinggi dibandingkan dengan kematian. Jumlah masyarakat perempuan dan laki-laki hampir sama. Agama yang paling mendominasi masyarakat Kelurahan Kertosari adalah Islam. 
$\begin{array}{lrr}\text { Penduduk } & \text { Kelurahan } & \text { Kertosari } \\ \text { memiliki } & \text { pekerjaan } & \text { yang } \\ \text { bervariasi. } & & \end{array}$

Dengan adanya jumlah penduduk yang sangat banyak dan wilayah yang luas, membuat sebagian wilayahnya berupa perumahan dan rumah yang padat penduduk. Lingkungan masyarakat yang bersih karena setiap RT selalu mengadakan kerja bakti untuk mencegah atau menghindari penyakit musiman seperti demam berdarah. Masyarakat Kelurahan Kertosari sebagian sadar akan kesehatan mereka sendiri, kesehatan masyarakatnya, dan kesehatan lingkungannya. Sebaliknya, masyarakat yang kurang sadar akan kesehatannya seperti acuh kepada kesehatan, cenderung menutup diri kepada lingkungan atau individualis.

Masyarakat yang kurang memperhatikan kesehatan, sering mengalami masalah-masalah kesehatan. Masyarakat yang memiliki masalah kesehatan dapat mendatangi puskesmas, atau polindes dan Posyandu Lansia atau Posyandu Balita yang telah disediakan oleh pihak Kelurahan Kertosari, Kecamatan Babadan, Kabupaten Ponorogo. Semua masyarakan seharusnya sadar akan kesehatannya tanpa diingatkan oleh orang lain. Menjaga kesehatan sangat penting karena di dalam jiwa yang sehat dapat melakukan kegiatan seharihari dengan mudah dan lancar.

2. Pelaksanaan Posyandu Lansia di Kelurahan Kertosari, Kecamatan Babadan, Kabupaten Ponorogo Tahun 2015

Kegiatan Posyandu Lansia diselenggarakan satu bulan sekali pada Rabu minggu pertama mulai pukul 07:00 WIB. Kegiatan ini dapat meningkatkan kesehatan masyarakat khususnya para lansia dan memberikan fasilitas kepada lansia untuk lebih berdaya guna di dalam kehidupannya. Hal ini karena lansia sering dianggap sebagai orang tua yang tidak mampu melakukan apa-apa. Dengan jiwa yang sehat dan kuat, lansia dapat melakukan aktivitas sebagaimana seharusnya. Kesehatan masyarakat sangatlah penting untuk meningkatkan pembangunan. Banyak 
masyarakat yang mengabaikan kesehatanya dan lebih memilih acuh sebelum masalah kesehatan yang dialaminya parah.

Kegiatan Posyandu Lansia yang pertama dilakukan yaitu kegiatan senam lansia yang dimulai pukul 07:00 WIB di halaman Balai Kelurahan Kertosari, Kecamatan Babadan, Kabupaten Ponorogo. Peserta yang mengikuti senam lansia diberikan baju olahraga yang seragam untuk meningkatkan kemauan para lansia mengikuti senam lansia dan berpartisipasi dalam kegiatan Posyandu Lansia. Para kader juga mengikuti senam dengan para lansia sehingga lansia dan kader dapat menjalin hubungan yang baik satu sama lain. Tidak ada kecanggungan dari semuanya.

3. Peranan Posyandu Lansia dalam meningkatkan kesehatan masyarakat di Kelurahan Kertosari, Kecamatan Babadan, Kabupaten Ponorogo Tahun 2015. Peranan Posyandu Lansia di Kelurahan Kertosari, Kecamatan Babadan, Kabupaten Ponorogo ada tiga yaitu sebagai pelayanan kesehatan, tempat konseling, dan tempat bersilaturahmi. Peranan Posyandu Lansia yang pertamasebagai pelayanan kesehatan. Pelayanan kesehatan yang diberikan dalam kegiatan Posyandu Lansia dikhususkan untuk para lansia namun tidak ada larangan apabila ada masyarakat yang ingin ikut serta. Pelayanan kesehatan di Posyandu Lansia meliputi pengukuran tinggi badan, penimbangan berat badan, pemeriksaan tekanan darah atau tensi, pemeriksaan gula darah dan kolesterol, pelayanan konseling sesuai kebutuhan lansia, penyuluhan kesehatan, dan senam serta pemberian vitamin atau Pemberian Makanan Tambahan (PMT).

Peranan Posyandu Lansia yang kedua yaitu sebagai tempat konseling bagi masyarakat atau lansia. Setelah semua kegiatan pelayanan kesehatan selesai, peserta yang ikut Posyandu Lansia dapat berkonseling atau curhat kepada tenaga Posyandu Lansia yang bertanggung jawab untuk memberikan konseling kepada peserta Posyandu Lansia. 
Konseling diberikan kepada lansia untuk dapat mengurangi beban yang dirasakan oleh lansia.Pada kegiatan konseling, lansia tidak hanya berkonsultasi masalah kesehatan melainkan juga masalah keadaan sosial, ekonomi ataupun masalah keluarga.

Peranan Posyandu Lansia
yang ketiga sebagai tempat
bersilaturahmi. Maksudnya bahwa
dalam kegiatan Posyandu Lansia,
masyarakat dapat berkumpul
untuk saling bersilaturahmi satu
sama lain sehingga yang tidak
kenal menjadi kenal, banyak
memiliki teman yang seusia, dan
dapat berkumpul antarlansia,
kader maupun tenaga
kesehatannya.

\section{SIMPULAN}

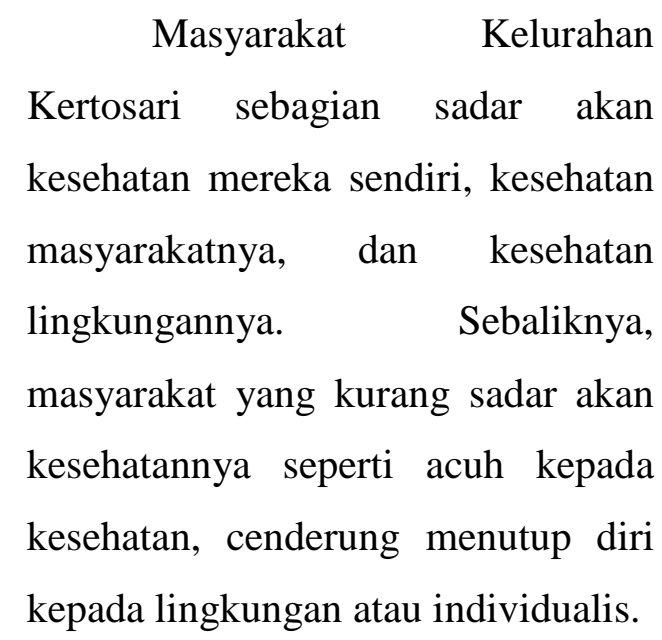

Masyarakat yang kurang memperhatikan kesehatan, sering mengalami masalah-masalah kesehatan. Masyarakat yang memiliki masalah kesehatan dapat mendatangi puskesmas, atau polindes dan Posyandu Lansia atau Posyandu Balita yang telah disediakan oleh pihak Kelurahan Kertosari, Kecamatan Babadan, Kabupaten Ponorogo.

Kegiatan Posyandu Lansia diselenggarakan satu bulan sekali pada Rabu minggu pertama mulai pukul 07:00 WIB.Kegiatan ini dapat meningkatkan kesehatan masyarakat khususnya para lansia dan memberikan fasilitas kepada lansia untuk lebih berdaya guna di dalam kehidupannya. Peranan Posyandu Lansia di Kelurahan Kertosari, Kecamatan Babadan, Kabupaten Ponorogo ada tiga yaitu sebagai pelayanan kesehatan, tempat konseling, dan tempat bersilaturahmi. 


\section{DAFTAR PUSTAKA}

Erfandi.2008. Pengelolaan Posyandu Lansia (Online), (http://puskesmasoke.blogspot.com/2009/0 4/pengelolaan-posyandulansia.html, diunduh 3 Maret 2015).

Fatmah. 2010. Gizi Usia Lanjut. Jakarta: Erlangga.

H. Herdiansyah. 2010. Metodologi Penelitian Kualitatif untuk Ilmu-Ilmu Sosial.Jakarta: Salemba Humanika.

Komisi Nasional Lanjut Usia. 2010. Pedoman Pelaksanaan Posyandu Lanjut Usia. Jakarta.

Lexy J. Moleong. 2002. Metodologo Penelitian Kualitatif. Bandung: PT Remaja Rosdakarya.

Nengah A. Oka. 2012. Masalah Kesehatan Masyarakat di Indonesia.

(Online),(https://aaknasio nal.wordpress.com/2012/ 03/12/masalah-masalahkesehatan-masyarakat-diindonesia/, diunduh 3 Maret 2015).

Sinta A. Anggraini. 2013. Mengatasi Problematika Kesehatan Masyarakat, (Online), (http://edukasi.kompasia na.com/2013/08/11/meng atasi-problematikakesehatan-masyarakat- 583444.html, diunduh 3 Maret 2015).

S. Notoatmodjo. 2003. Ilmu Kesehatan Masyarakat. Jakarta: Rineka Cipta.

2005. Promosi Kesehatan Teori dan Aplikasi.Jakarta: Rineka Cipta.

Sugiyono. 2013. Metode Penelitian Kuantitatif Kualitatif dan $R \& D$. Bandung:

Alfabeta.

Undang-Undang Republik Indonesia Nomor 36 Tahun 2009 Tentang Kesehatan

Wahid I. Mubarak dkk. 2009. Ilmu Kesehatan Masyarakat:Teori dan Aplikasi. Jakarta: Salemba Medika. 